\title{
Pulmonary infections in HIV-infected patients: an update in the 21 st century
}

\author{
N. Benito*, A. Moreno", J.M. Miro" and A. Torres ${ }^{\tau,+}+$
}

ABSTRACT: From the first descriptions of HIV/AIDS, the lung has been the site most frequently affected by the disease. Most patients develop a pulmonary complication during the history of HIV infection, mainly of infectious aetiology.

Important changes in the epidemiology of HIV-related pulmonary infections have occurred. Overall, prescription of Pneumocystis jirovecii prophylaxis and the introduction of highly active antiretroviral therapy (HAART) are the main causes.

Currently, the most frequent diagnosis in developed countries is bacterial pneumonia, especially pneumococcal pneumonia, the second most frequent cause is Pneumocystis pneumonia and the third is tuberculosis. However, in Africa, tuberculosis could be the most common pulmonary complication of HIV.

Pulmonary infections remain one of the most important causes of morbidity and mortality in these patients, and the first cause of hospital admission in the HAART era. Achieving an aetiological diagnosis of pulmonary infection in these patients is important due to its prognostic consequences.

KEYWORDS: AIDS, bacterial pneumonia, HIV, Pneumocystis pneumonia, pulmonary infections, tuberculosis

$\mathbf{T}$ he first published reports of AIDS appeared in 1981, when five homosexual males in Los Angeles (CA, USA) were diagnosed with Pneumocystis carinii (currently Pneumocystis jiroveci) pneumonia [1]. Since then, $\mathrm{HIV}$ infection has become a pandemic and remains one of the most important global health problems of the 21st century [2]. The number of people living with HIV is increasing worldwide because of ongoing accumulation of new infections (even at a reduced rate) with longer survival times. There were 33.3 million people worldwide living with $\mathrm{HIV}$ at the end of 2009 compared with 26.2 million in 1999; a $27 \%$ increase [2].

Combination therapy with multiple agents against HIV, known as HAART (highly active antiretroviral therapy), became widely used between 1996 and 1997 in developed countries. As a result, the incidence of opportunistic infections has decreased and the life expectancy of HIV-infected persons has increased [3, 4]. However, this has not occurred uniformly worldwide because antiretroviral therapy (ART) is not yet available to millions of HIVinfected people, mainly in resource-limited countries. Moreover, a significant percentage of patients in developed countries are not receiving HAART because they have a delayed HIV diagnosis (i.e. an advanced stage of disease at diagnosis) or they are not in active care despite the availability of HAART $[5,6]$.

From the first descriptions of HIV/AIDS, the respiratory tract has been the site most frequently affected by the disease. According to results of autopsy findings, the lung was affected with an incidence ranging from $100 \%$ in the early period of the epidemic to $70 \%$ in the HAART era [7-11]. Up to $70 \%$ of HIV patients have a pulmonary complication during the evolution of the disease, mainly of infectious aetiology [11]. Lower respiratory tract infections are 25-fold more common in patients with HIV than in the general community, occurring in up to 90 cases per 1,000 person-yrs [12]. Currently, pulmonary infections, not only AIDS-related opportunistic infections, remain a leading cause of morbidity and mortality and one of the most frequent causes of hospital admission in HIV infected people worldwide [13]. An incidence of 20-25 episodes per 100 hospital admissions per year has been observed $[14,15]$. These numbers give an idea of the magnitude of the problem of pulmonary infections in HIV patients. Moreover, it has been suggested that Pneumocystis pneumonia (PCP),

\section{AFFILIATIONS}

*Infectious Diseases Unit, Internal Medicine Service, Hospital de la Santa Creu i Sant Pau, Universitat Autonoma de Barcelona,

"Infectious Diseases Service,

-Pneumology Service, Hospital Clínic-IDIBAPS, Universitat de

Barcelona, and

${ }^{+}$CIBERES, Barcelona, Spain.

\section{CORRESPONDENCE}

N. Benito

Infectious Diseases Unit, Internal

Medicine Service

Hospital de la Santa Creu i Sant Pau

Sant Antoni Maria Claret

167

Barcelona 08025

Spain

E-mail: nbenito@santpau.cat

Received:

Dec 282010

Accepted after revision:

Aug 152011

First published online:

Sept 012011

Online ISSN 1399-3003 
tuberculosis (TB) and bacterial pneumonia are associated with a significantly worse subsequent HIV disease course, even a permanent decline in pulmonary function [16-19], although not all studies agree with these findings [20].

\section{EPIDEMIOLOGY OF PULMONARY INFECTIONS IN HIV- INFECTED PATIENTS}

Few studies have systematically described the full spectrum of HIV-associated pulmonary infections [14, 21-23]. Most investigators have focused on pneumonias of specific aetiologies. Therefore, there is no consensus on any diagnostic algorithm of pulmonary infections in HIV patients. The diagnostic decision should be different depending on the epidemiological features in a specific geographical area [24]. Thus, the incidence of TB in HIV patients varies considerably in different geographical areas, depending on the prevalence of disease in the general population. In Africa, TB could be the most common pulmonary complication of HIV, followed by community-acquired pneumonia [23, 24]. However, PCP is uncommon in Africa, although the incidence seems to be increasing [24-26]. It remains speculative whether this trend denotes a true increase in the prevalence of PCP or whether the early reports underestimated the actual prevalence [25]. In Western Europe in the 1990s, PCP was the commonest AIDS-defining illness, whereas pulmonary TB was more common in Eastern Europe. Within Western Europe, TB remains more common in the south than in the north [27]. Endemic fungi are common in HIV patients who live in endemic areas, but are exceptional in patients that have never resided in or travelled to endemic regions [28].

The epidemiology of pulmonary infections in HIV has notably changed in the last decades. There are several explanations for these changes. The general prescription of PCP primary prophylaxis since 1989 is one of the main causes, and the use of HAART since 1996 is other underlying explanation. After PCP prophylaxis, the incidence of Pneumocystis infection greatly decreased in the USA and Europe. Additionally, some studies have suggested that prophylaxis with trimethoprim-sulfamethoxazole (TMP-SMX) could have decreased the incidence of bacterial infections in HIV patients with <200 CD4 lymphocytes per $\mathrm{mm}^{3}$; however, not all studies agree with this statement [29, 30]. Following the introduction of HAART, the relative incidence of aetiologies of HIV-associated pulmonary infections has changed, with bacterial pneumonia replacing PCP as the most frequently encountered cause of these infections [30, 31]. Nevertheless, the influence of HAART on the incidence and prognosis of pulmonary diseases, mainly on non-opportunistic infections and malignancies, is still not well known.

The risk of developing each infection is strongly influenced by the degree of inmunosuppression, the patient's demographic characteristics, the place of current or previous residence, and whether they are using prophylaxis against common HIVassociated infections [28]. Genetic factors are probably important but have been less precisely defined.

\section{PULMONARY INFECTIONS IN PATIENTS WITH HIV INFECTION}

Bacterial pneumonia is currently the most frequent cause of pulmonary infections in HIV-infected patients, followed by PCP and $\mathrm{TB}$, with different incidences depending on geographical area (table 1) [14, 15, 32]. In addition, endemic fungi, parasites

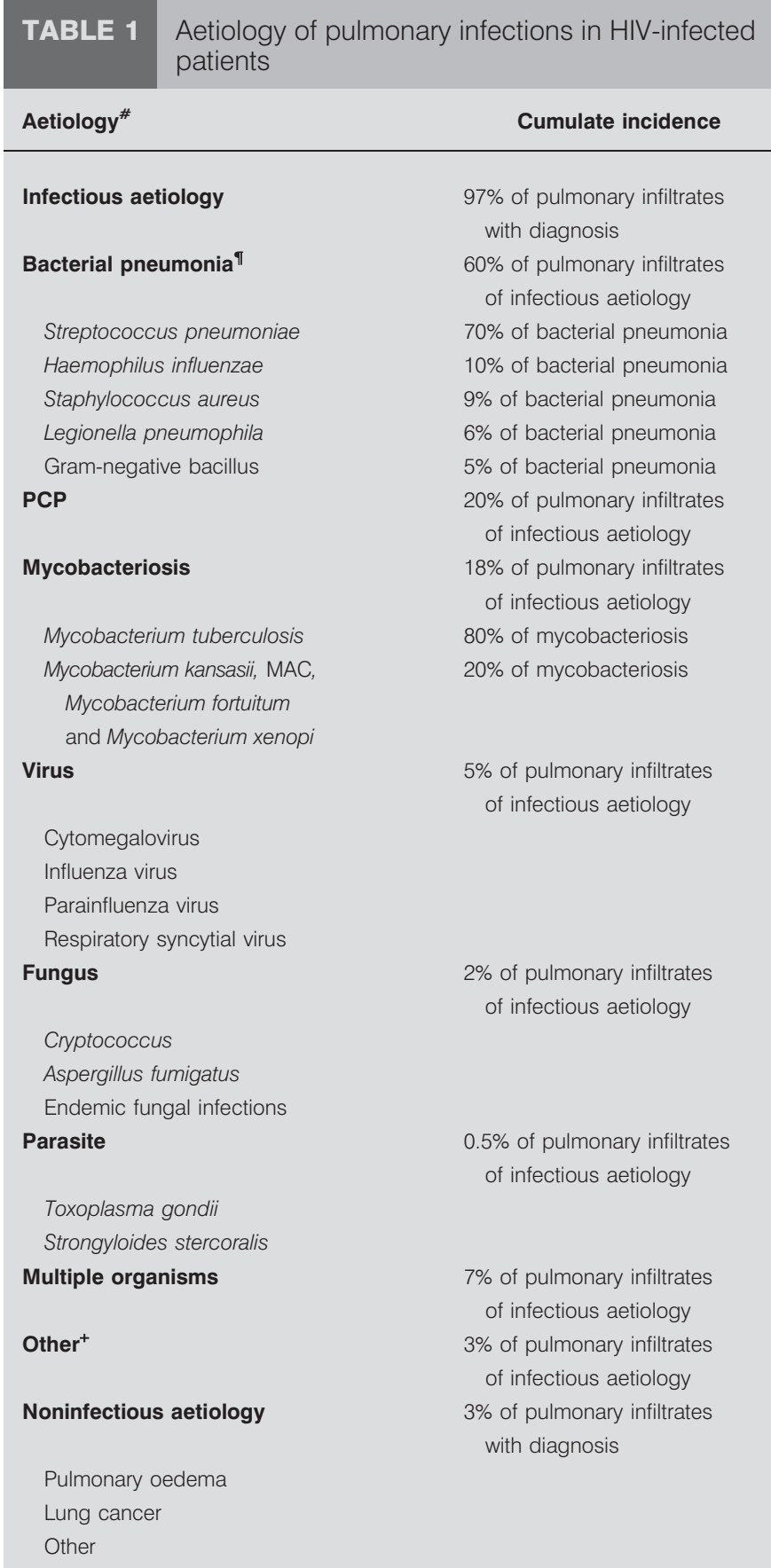

PCP: Pneumocystis pneumonia; MAC: Mycobacterium avium complex. ${ }^{*}$ : incidence of different aetiologies can vary in different geographical areas; ": percentage of each microorganism causing bacterial pneumonia is estimated among cases of bacterial pneumonia with identification of aetiology; ${ }^{+}$: bronchiectasis and pulmonary abscess. Data are based on results from $[10,11,24]$

and viruses contribute substantially to the burden of pulmonary disease in patients infected with HIV worldwide.

\section{Bacterial pneumonia}

Currently, bacterial pneumonia is the most frequent infection in HIV-infected patients, as well as the most common admission 
diagnosis $[14,15,33]$. HIV infection is associated with a $>10$-fold increased incidence of bacterial pneumonia [12, 18].

Intravenous drugs and smoking are risk factors for the development of bacterial pneumonia in this group of patients [29, 33-35]. Smoking is associated with a two- to five-fold increase in the risk $[18,33]$. Other risk factors include older age, detectable HIV load and previous recurrent pneumonia [35]. Bacterial pneumonia can occur throughout the entire course of HIV infection, but the incidence increases as CD4 cell numbers decrease [21, 29, 33]. 80\% of cases of bacterial pneumonia occur with a CD4 count $<400$ cells per $\mathrm{mm}^{3}$, and recurrent pneumonia with a CD4 count $<300$ cells per $\mathrm{mm}^{3}$. The Centers for Disease Control (CDC) added recurrent bacterial pneumonia as an AIDS-defining condition in 1992. The median CD4 lymphocyte count in cases of bacterial pneumonia is 200 cells per $\mathrm{mm}^{3}$, significantly higher than the median CD4 lymphocyte count in TB or PCP [14]. Moreover, the median HIV load is lower in bacterial pneumonia than in TB or PCP [14]. Recently, it has been demonstrated that the control of viral load has a significant impact on the development of bacterial pneumonia [33].

Relatively few reports have characterised the impact of HAART on bacterial pneumonia [27]. Several observational studies have shown that HAART would be associated with a decrease in the incidence rate of bacterial pneumonias [36, 37]. In patients with $<200$ CD4 cells per $\mathrm{mm}^{3}$, this decline could be very important [37]. Moreover, the greatest impact of HAART would be on decreasing nosocomial infections rather than communityacquired infections [38]. Data from a randomised trial of continuous versus intermittent ART showed that the risk of pneumonia was significantly higher among patients treated with intermittent treatment [33]. In this study, ART reduced the risk of bacterial pneumonia, even for persons with CD4 cell counts of $\geqslant 500$ [33]. However, the relative percentage of bacterial pneumonias as the cause of pulmonary infiltrates would have increased in recent years whilst the percentage of opportunistic infections would have decreased [14, 15].

As in the general population, Streptococcus pneumoniae is the most common bacterial cause of community-acquired pneumonia among HIV-infected adults, implicated in $\sim 20 \%$ of all bacterial pneumonias ( $40 \%$ of those for which a specific diagnosis is made) [12]. There are conflicting data as to whether the incidence of invasive pneumococcal disease per se has declined during the post-HAART era. Of note is the increased rate of bacteraemia complicating pneumococcal pneumonia among HIV-infected people ( $>50 \%$ in some studies), and the high rates of recurrent pneumococcal pneumonia (10-25\%) [39].

Data regarding the effectiveness of pneumococcal vaccination in HIV-positive patients are still controversial $[12,13]$. A clinical trial of pneumococcal polysaccharide vaccine paradoxically determined that an increased risk of pneumonia was associated with vaccination [40, 41]. However, several observational studies have reported benefits from vaccination with the 23-valent pneumococcal polysaccharide vaccine in HIV-infected adults [42-47]. Studies have also shown that vaccination is associated with a lower risk of pneumococcal bacteraemia [45, 48]. Most HIV specialists believe that the potential benefit of pneumococcal vaccination outweighs the risk. In 1999, the CDC and the Infectious Disease Society of America (IDSA) guidelines recommended that a single dose of polysaccharide vaccine should be given as soon as possible after the diagnosis of HIV infection to adults with a CD4 T-cell count $>200$ cells per $\mathrm{mm}^{3}$ who had not received one during the previous 5 yrs [49]. HIV-infected adults who have a CD4 count of $<200$ cells $\cdot \mu \mathrm{L}^{-1}$ can be offered pneumococcal polysaccharide vaccine. Clinical evidence has not confirmed efficacy in this group, but there is some evidence of benefit in those who also start HAART [45]. Revaccination can be considered for persons who were initially immunised when their CD4 counts were $<200$ cells $\mu \mathrm{L}^{-1}$ and whose CD4 counts have increased to $>200$ cells $\mu \mathrm{L}^{-1}$ in response to ART [50]. The duration of the protective effect of primary pneumococcal vaccination in HIVinfected patients is unknown. Although no evidence confirms clinical benefit from revaccination, it may be considered every 5 yrs [50]. Despite these recommendations, pneumococcal polysaccharide vaccine has been under used in HIV-infected adults. A clinical trial evaluating a 9-valent pneumococcal conjugate vaccine in children showed beneficial effects by reducing the incidence of a first episode of invasive disease caused by serotypes included in the vaccine [51]. Additional, there was a strong effect on reduction of virus-associated pneumonias. In a recent clinical trial, the 7valent pneumococcal conjugate vaccine was shown to protect HIVinfected adults from recurrent pneumococcal infection caused by vaccine serotypes or serotype 6A [52].

Haemophilus influenzae accounts for $10-15 \%$ of cases of bacterial pneumonia with aetiological diagnosis $[14,15,53]$. The epidemiological and clinical characteristics of pneumonia caused by $H$. influenzae in this group of patients have been described previously [53]. It mainly affects patients with advanced HIV disease, and a subacute clinical presentation has been observed in $\sim 30 \%$ of cases. More than half of patients have bilateral lung infiltrates.

In contrast to the noninfected population, Pseudomonas aeruginosa and Staphylococcus aureus are both reported as communityacquired pathogens with an increased frequency in persons with HIV infection [54, 55].

S. aureus is the third most frequent cause of bacterial pneumonia $[14,15]$. Injection drug users can develop right-sided tricuspid valvular $S$. aureus endocarditis with septic pulmonary emboli (small, peripheral, circular lesions that may cavitate with time). Most affected patients have no history of antecedent valvular damage.

Although $P$. aeruginosa was frequently found to be an aetiological agent of bacterial pneumonia in early studies [29], currently, only a few episodes are caused by this microorganism [14, 15]. In early studies performed in the pre-HAART era, there was a higher incidence of nosocomial pneumonia and $P$. aeruginosa was a frequent microorganism in these cases [56]. Moreover, communityacquired bronchopulmonary infections due to $P$. aeruginosa in patients with a very advanced immunosupression state (typically $<50$ CD4 lymphocytes $\cdot \mathrm{mL}^{-1}$ ) have been described. After the introduction of HAART, patients remain in this state for a shorter period of time, and hospitalisation of HIV patients has decreased. Consequently, infections caused by these microorganisms have also declined.

Legionella infection is uncommon, but some studies suggest that it occurs up to 40 times more frequently in patients with AIDS than in the general population [57]. Some authors have described a worse prognosis in HIV patients with Legionella pneumonia, with 
higher number of complications; however, other studies showed few significant differences [57].

Other uncommon infections include Rhodococcus and Nocardia. Rhodococcus equi can cause pulmonary infection in patients with HIV infection, generally in the setting of advanced immunosuppression. R. equi pneumonia is characterised by an indolent course with fever, cough and cavitary infiltrates, mimicking TB. Treatment is based upon antimicrobial sensitivity testing. Although nocardiosis is not very common in HIV-infected patients $(0.2-2 \%)$, due, at least in part, to prophylaxis with TMPSMX, the incidence is approximately $>140$-fold in these patients than in the general population, particularly in those with CD4 count $<100$ cells per $\mathrm{mm}^{3}$ [58]. Radiographic findings of lung involvement include single or multiple nodules or masses (with or without cavitation), interstitial infiltrates, lobar consolidation and pleural effusions. Nocardiosis has frequently been misdiagnosed initially as TB (since upper lobe involvement is common and Nocardia spp. are weakly acid fast), invasive fungal disease and malignancy. Because of the propensity for Nocardia spp. to cause central nervous system infection, brain imaging should be performed in all patients with pulmonary nocardiosis. Sulfonamides are the most common drugs used for treatment [59].

Pneumonia due to Mycoplasma pneumoniae and Chlamydia pneumoniae appears to be relatively uncommon in patients with HIV infection, although the role of these pathogens has not been studied systematically.

The clinical presentation of bacterial pneumonia in HIVseropositive patients is usually similar to that of patients not infected with HIV. Bacteraemia is frequently associated with bacterial pneumonia. The most common chest roentgenographic manifestation is unilateral segmental or lobar consolidation, although diffuse reticulonodular infiltrates and patchy lobar infiltrates may also be identified. A subset of persons with $H$. influenzae pneumonia present with bilateral infiltrates that are indistinguishable from PCP. However, pneumonia due to $P$. aeruginosa or $S$. aureus is often associated with cavitation.

The initial antibiotic treatment regimen will be directed at the most common pathogens. Treatment is similar to that of patients with the same diagnosis without HIV infection.

\section{Pneumocystis pneumonia}

PCP is caused by $P$. jirovecii, a ubiquitous organism that is classified as a fungus but that also shares biological characteristics with protozoa. Whereas the primary mode of transmission of $P$. jirovecii is uncertain, there are increasing data supporting the possibility of airborne transmission of this microorganism [60, 61]. This would support the recommendation to avoid placing an immunocompromised patient in the same room as a patient with PCP [60]. Pneumocystis may colonise the respiratory tract in the absence of clinical signs or symptoms of infection; although the clinical significance of colonisation is not well understood, patients who are colonised with Pneumocystis could serve as a pathogen reservoir [62].

Early studies in the USA showed PCP as the most frequent cause of pulmonary infections (accounting for $85 \%$ of cases) and the first cause of hospital admission in HIV patients [7, 63]. It was estimated that $75 \%$ of these patients would develop PCP during their lifetime [64]. The rate of PCP greatly decreased in developed countries as a result of primary $P$. jirovecii prophylaxis in 1987 and, more recently, the widespread administration of HAART [65-67]. Despite this decrease, PCP remains the most common AIDS-defining indicator condition and the most frequent opportunistic infection in North America and Europe [27]. Nevertheless, $P$. jirovecii pneumonia still occurs in persons who are not receiving either HAART or anti-PCP prophylaxis; a significant percentage of these patients (up to 50\%) are not known to be infected with HIV [68]. This situation emphasises the importance of performing an early diagnosis of HIV infection, especially in patients at risk $[5,68]$.

PCP mainly develops in patients whose CD4 cell count is $<200$ cells $\cdot \mathrm{mL}^{-1}$. The median CD4 count is 20 cells per $\mathrm{mm}^{3}$, and the plasma viral load of HIV is usually $>10,000$ copies $\cdot \mathrm{mL}^{-1}$ [14].

HIV-infected persons with PCP generally have a more sub-acute course and longer duration of symptoms than other immunocompromised patients. The clinical presentation consists of fever, gradually increasing nonproductive cough and dyspnoea for a few weeks, bilateral interstitial infiltrates and high alveolararterial gradients. The most common findings on physical examination are fever, tachypnoea and inspiratory crackles, but physical examination of the chest is unremarkable in $\sim 50 \%$.

Chest radiographs are initially normal in up to a quarter of patients with PCP. The chest radiograph typically demonstrates perihilar infiltrates in mild disease and bilateral, symmetrical interstitial infiltrates emanating from the hila in a butterfly pattern in severe disease [69]. Less frequently, PCP may present with unilateral or asymmetrical opacities. Thin-walled cysts or pneumatoceles are seen in $10-20 \%$ of cases. Pneumothorax can occur; in fact, suspicion of PCP should increase when pneumothorax is observed in a patient with HIV infection. Cavitation, intrathoracic adenopathy and pleural effusion are uncommon; their presence might indicate an alternative diagnosis. Highresolution computed tomography (HRCT) has a high sensitivity for PCP $(100 \%)$ and a specificity of $89 \%$ [70, 71]. A negative HRCT may allow exclusion of PCP.

The most common abnormal laboratory value associated with PCP in HIV-infected patients is elevated lactate dehydrogenase (LDH) level, present in $90 \%$ of patients and with a prognostic significance [72]. However, an elevated LDH level may occur with other pulmonary diseases, especially mycobacterial and fungal infections. Recently, low levels of plasma $S$-adenosylmethionine were shown to be sensitive and specific indicators of PCP; in addition, the levels increased with successful treatment of PCP [73]. More recently, high levels of blood $(1 \rightarrow 3)-\beta$-D-glucan have demonstrated a good correlation with HIV-related PCP, although the precise role of this test remains to be defined [74]. Although PCP can be suspected based upon clinical and radiological findings, the diagnosis should usually be confirmed.

Specific diagnosis of PCP requires microscopic visualisation of the characteristic cysts and/or trophic forms on stained respiratory specimens. It is usually performed by bronchoalveolar lavage (BAL), induced sputum and, on rare occasions, lung biopsy [13]. Bronchoscopy with BAL is the preferred diagnostic procedure for PCP, with reported sensitivity of $90-98 \%$. The most rapid and least invasive method of diagnosis is by analysis of sputum induced by the inhalation of hypertonic saline. While the specificity of this method approaches $100 \%$, the sensitivity ranges 
from $55 \%$ to $92 \%$ [75]. This variability is specially related to the skills of the team inducing the sputum [76]. Several PCR assays have been developed for the diagnosis of PCP, and have been tested on BAL, induced sputum and noninvasive oral wash specimens [77]. In general, PCR assays have been more sensitive but less specific for diagnosis of PCP than traditional microscopic methods. Currently, PCR-based tests are not in widespread use. Treatment can be initiated before making a definitive diagnosis because organisms persist in clinical specimens for days or weeks after effective therapy is initiated [78].

TMP-SMX remains the drug of choice for the treatment and prevention of this infection, but the best choice of alternative agents has not yet been established. The occurrence of PCP in patients who are compliant with TMP-SMX prophylaxis is highly unusual, but it is relatively more common in patients receiving other prophylaxis strategies. The recommended duration of therapy for PCP is 21 days and, following the completion of therapy, patients should be immediately started on PCP prophylaxis [50]. Corticosteroids given in conjunction with antiPneumocystis therapy decrease the mortality associated with severe PCP, particularly in patients with abnormalities in oxygen exchange at the time of presentation (partial pressure of oxygen $<70 \mathrm{mmHg}$ or an arterial-alveolar oxygen pressure difference $>35 \mathrm{mmHg}$ ) [50,79]. Certain strains of $P$. jirovecii have mutations in the dihydropteroate synthase (DHPS) gene, an essential enzyme that is inhibited by sulfonamides. The DHPS mutation is associated with the use and duration of TMP-SMX prophylaxis, but it is not related to a possible failure of TMP-SMX treatment and a worst prognosis [68, 80-82]. Once immunological response is documented and sustained with the use of HAART (CD4 cell count increase $>200$ cells $\cdot \mathrm{mL}^{-1}$ for at least 3 months), PCP prophylaxis may be discontinued $[50,83]$. Recently, an observational study has suggested that discontinuation of prophylaxis may be safe in patients with CD4 counts of $101-200$ cells $\cdot \mathrm{mL}^{-1}$ and suppressed viral load [84]. Alternative regimens of treatment and prevention of $\mathrm{PCP}$ can be reviewed in the most recent guidelines of CDC/IDSA [50].

\section{TB and other mycobacteriosis}

The coincidence of TB and HIV epidemics has created a devastating international public health crisis. At least one-third of HIV-infected persons worldwide are infected with Mycobacterium tuberculosis, and HIV infection is, in global terms, the largest risk factor for developing TB disease [85]. Additionally, TB is a leading cause of death for people living with HIV in low- and middle-income countries [86]. HIV-infected persons have a substantially greater risk of progressing from latent TB infection to active TB compared with persons without HIV infection $[87,88]$. The use of HAART has been found to be associated with a notable reduction in the risk of $\mathrm{TB}$, but incidence rates remain higher than in the general population [8992]. In a study of patients initiating HAART over a follow-up period of $4.5 \mathrm{yrs}$, the risk of TB only decreased when the CD4 threshold was $>500$ cells per $\mathrm{mm}^{3}$ [93].

Africa is experiencing the worst TB epidemic since the advent of antibiotics, with rates increasing sharply in the past two decades [86, 94, 95]. Conversely, in the USA and Western Europe, a decline in the incidence of TB in HIV-infected patients has been observed in the last decades; however, remarkable regional differences have been found in Europe, with rates four to seven times higher in southwest Europe than in other European regions $[96,97]$.

TB can occur at any stage of HIV disease, but as the CD4 cell count declines, the incidence of TB increases. Persons at risk for increased exposure include residents and employees of healthcare facilities, prisons and homeless shelters; the disease can be found at high rates among intravenous drug users.

Clinical manifestations largely depend on the level of immunosuppression. In persons whose CD4 cell count is $>350-400$ cells per $\mathrm{mm}^{3}$, the clinical presentation is similar to that in persons without HIV infection. Typically, these persons have disease that is limited to the lungs and they present with a reactivation of the TB radiographic pattern (upper lung zone fibronodular infiltrates with or without cavitation). Persons whose CD4 cell count is $<200$ cells per $\mathrm{mm}^{3}$ often present with a primary TB pattern (middle and lower lung zone infiltrates, lymph node enlargement or a milliary pattern); cavitation is less common, and the chest radiograph may also be normal. Patients with advanced immunosuppression more often have extra-pulmonary and disseminated TB. Subclinical TB is increasingly recognised. In fact, there is a subpopulation of individuals with HIV with culture-positive pulmonary TB who are completely asymptomatic [92].

The most important diagnostic tests for $\mathrm{TB}$ are repeated expectorated sputum samples for smear and culture; three samples should be collected, preferably early in the morning on different days. In some studies, two specimens collected on the same day would give similar results [85]. Sputum induction by nebulisation of hypertonic saline is also a useful method in patients unable to produce expectorated sputum or if sputum is smear negative. In patients with low CD4 counts (especially $<100$ cells per $\mathrm{mm}^{3}$ ) disseminated TB is common, and cultures of blood and urine have a good yield. Cultures on selective media remain the most sensitive method for detecting $M$. tuberculosis in clinical specimens. Testing for susceptibility to first-line agents should be performed on all isolates. Nucleic acid amplification testing amplifies the quantity of $M$. tuberculosis DNA in diagnostic specimens, and is useful for rapid identification of the microorganism. The sensitivity of these tests compared with culture is $\sim 95 \%$ in patients with a positive acid-fast bacilli smear, but in persons with acid-fast bacilli smear-negative sputum or extra-pulmonary disease, nucleic acid amplification tests have lower sensitivity and negative predictive value, and should be used and interpreted with caution [98]. Specificity is very high $(>95 \%)$. The appropriate use of these tests has yet to be completely determined. Recently, the assay Xpert ${ }$ MTB/RIF (Cepheid ${ }_{\circledR}$, Sunnydale, CA, USA), an automated nucleic acid amplification test, was shown to provide a sensitive detection of $\mathrm{TB}$ and rifampin resistance directly from sputum in $<2 \mathrm{~h}$ [99]. This test can speed up the diagnosis, control and treatment of multidrug-resistant TB.

The principles of TB treatment in HIV-infected individuals are the same as those in HIV-negative individuals [50]. However, treatment of TB can be complicated by drug interactions and overlapping toxicities when therapy for both HIV and TB is concomitantly administered. Rifamycins (mainly rifampin, but also rifabutin) induce hepatic CYP3A4 enzymes that can accelerate metabolism of protease inhibitors (PIs) and non-nucleoside 
reverse transcriptase inhibitors (NNRTIs) leading to sub-therapeutic levels of these antiretroviral drugs. Rifampin should not be used in patients on PI-based regimens; although rifampin lowers levels of both the NNRTIs (efavirenz and nevirapine), the former is less affected. Rifabutin is an alternative to rifampin that can be administered with PIs or NNRTIs with appropriate dose adjustments. Recent studies suggest that rifampin plays a key role in the treatment of HIV-associated TB: recurrence rates are two to four times higher when rifampin is not included in the continuation phase (after the first 2 months of therapy) [85, 100]. Rifampin-based TB treatment with efavirenz-based ART is probably the preferred treatment approach for HIV-associated TB [101]. Regarding the optimal timing of starting ART in these patients, several clinical trials have demonstrated the clinical benefit of initiating ART during TB therapy, rather than at later time intervals [102-105]. Early HAART (initiated during the first 2 weeks) reduced the HIV disease progression and death among HIV-infected HAART-naïve patients with TB and a CD4 cell count of $<50$ cells per $\mathrm{mm}^{3}$. In patients with CD4+ T-cells $>50$ cells per $\mathrm{mm}^{3}$, HAART can be started within 8 weeks after the start of TB treatment. HAART should never be delayed until after the completion of the TB therapy, at least for patients with CD4 T-cells counts $\leqslant 500$ cells per $\mathrm{mm}^{3}$ [102]. The risk of immune reconstitution inflammatory syndrome (IRIS) was higher among patients who started ART at earlier time-points, but there were no deaths related specifically to IRIS. A clinical trial showed that treatment with prednisone for 1 month reduced the incidence of IRIS in patients with pulmonary TB who started HAART at the same time as TB treatment [106]. World Health Organization (WHO) guidelines recommend that, irrespective of CD4 cell counts, patients co-infected with HIV and TB should be started on antiretroviral therapy as soon as TB therapy is tolerated [107]. More detailed information on the treatment of TB in HIV patients and management of drug interactions can be reviewed in the most recent guidelines of CDC/IDSA [50, 108].

In developed settings, all persons should be tested for latent TB infection at the time of HIV diagnosis, and they should be treated if they have a positive diagnostic test for latent TB infection, no evidence of active TBs and no prior history of treatment for active or latent TB [50]. The tuberculin skin test has been the usual method to determine latent TB infection. Recently, the development of interferon (IFN)- $\gamma$ release assays has been an important advance in the diagnosis of latent TB infection. However, sensitivity of INF- $\gamma$ release assays could be diminished by HIV infection [109, 110]; lower CD4 counts have been associated with higher rates of indeterminate results of these assays [109]. Recent WHO guidelines for prevention of TB in HIV-infected patients in resource limited settings recommend that persons living with HIV should be screened for TB with a clinical algorithm; those patients who do not report any of the symptoms of current cough, fever, weight loss or night sweats are unlikely to have active TB and should be offered treatment of latent infection [111]. Performing a tuberculin skin test would not be a requirement for initiating treatment of latent infection [111]. Treatment options for latent TB infection include isoniazid daily or twice weekly for 9 months. A recently published clinical trial shows that a 12-week course of isoniazid plus rifamycin may be an effective alternative [112].

Pulmonary infections due to Mycobacterium sp. other than TB are also seen with increased frequency in HIV-infected persons. Infections with at least 12 different mycobacteria have been reported; the most common is Mycobacterium avium complex (MAC). Infections with MAC are seen mainly in the USA and are rare in Africa. MAC infection predominantly occurs in patients with CD4 cell counts of $<50$ cells $\cdot \mathrm{mL}^{-1}$. The most common presentation is disseminated disease. The chest radiograph is abnormal in $\sim 25 \%$ of patients. The most common pattern is a bilateral, lower lobe infiltrate suggestive of miliary spread; alveolar or nodular infiltrates and hilar and/or mediastinal adenopathy can also occur. The finding of two consecutive sputum samples positive for MAC is highly suggestive of pulmonary infection. Therapy consists of a macrolide, usually clarithromycin, with ethambutol [50]. A third drug from among rifabutin, ciprofloxacin or amikacin can be added in patients with extensive disease. It is possible to discontinue therapy in patients with sustained suppression of HIV replication and CD4 cell counts $>100$ cells $\cdot \mathrm{mL}^{-1}$ for $>6$ months.

In a study in an endemic area in southern Europe, mycobacteriosis was the third cause of pulmonary infiltrates in HIV patients [15]. This high rate, together with the frequent association of mycobacteriosis with other pulmonary infections, supports the performance of routine Mycobacterium cultures in all HIV patients with pulmonary infiltrates in endemic areas [15].

\section{Fungal infections other than PCP}

Some studies suggest a decline in the incidence of endemic fungal infections since the introduction of HAART. This is difficult to demonstrate, as the incidence of these infections has not been fully determined [50, 113]. The three major endemic fungi are Histoplasma capsulatum, Coccidiodes inmitis and Blastomyces dermatitidis. They are acquired by inhalation. These diseases can represent primary infection caused by exogenous exposure or reactivation of a latent focus. Infections in patients who reside outside endemic regions generally represent reactivation of latent foci of infection from previous residence in these areas [114]. Reactivation may occur even years after moving to other geographic areas. Endemic areas include the southwest USA, northern Mexico and parts of Central and South America.

Histoplasmosis is the most common endemic mycosis in HIV patients. Most cases of disseminated histoplasmosis and coccidioidomycosis occur with CD4 lymphocyte counts $\leqslant 100$ cells per $\mathrm{mm}^{3}$, but focal pneumonia is the most common in those with a CD4 cell count $>250$ cells per $\mathrm{mm}^{3}$. Blastomycosis is an uncommon, but serious complication in HIV-infected persons. All of these endemic fungal infections have a wide spectrum of manifestations in HIV-infected patients with frequent lung involvement. Treatment is based on amphotericin B and triazoles $[50,115]$.

Discontinuing suppressive azole therapy appears to be safe for patients with histoplasmosis who had: received itraconazole therapy for $\geqslant 1 \mathrm{yr}$; negative blood cultures; histoplasma serum antigen of $<2$ enzyme immunoassay units; a CD4 cell count $>150$ cells per $\mathrm{mm}^{3}$; and been on HAART for 6 months $[50,116]$. In patients with focal coccidioidal pneumonia who had responded to antifungal therapy, were receiving ART and had a CD4 count cell $>250$ cells per $\mathrm{mm}^{3}$, it would be possible to discontinue secondary prophylaxis after 12 months of therapy. However, in patients with diffuse pulmonary disease or disseminated coccidioidomycosis, therapy should be continued indefinitely. Patients receiving ART who have had a CD4 cell count of 
$>150$ cells per $\mathrm{mm}^{3}$ for $\geqslant 6$ months can discontinue itraconazole therapy for blastomycosis after a minimum of $1 \mathrm{yr}$ [50].

Penicillium marneffei (penicilliosis) is endemic in southeast Asia, southern China and, more recently, in India. Penicilliosis is an important cause of morbidity and mortality in HIV-infected patients living in endemic areas or who have had travel-related exposure to this organism; the use of HAART has led to a significant decline of its incidence. The majority of cases are observed in patients who have CD4 counts of $<100$ cells $\mu \mathrm{L}^{-1}$. Patients commonly present disseminated disease, and the respiratory system is commonly involved (reflecting the probable inhalational route of acquisition).

The recommended treatment is amphotericin B followed by oral itraconazole. All patients who successfully complete treatment for penicilliosis should be administered secondary prophylaxis with oral itraconazole. Discontinuing secondary prophylaxis for penicilliosis is recommended for patients who receive ART and have a CD4 count $>100$ cells per $\mathrm{mm}^{3}$ for $\geqslant 6$ months [50].

When cryptococcosis occurs in HIV-infected persons, disseminated disease is common and most patients present with meningitis. The lungs are the portal of infection and the second most clinically relevant site of infection after the central nervous system. The number of cryptococcosis cases has declined significantly in developed countries following the introduction of HAART [117]. The presentation of pulmonary cryptococcosis in HIV-infected persons appears to be more acute than in other hosts. The severity of symptoms and extent of dissemination are inversely proportional to the CD4 lymphocyte count; most symptomatic cases occur in patients with $<100$ cells per $\mathrm{mm}^{3}$. Cryptococcal pneumonia in HIV patients most commonly presents with diffuse bilateral interstitial infiltrates that often mimics PCP [118]. In addition, unilateral interstitial infiltrate, focal consolidation, nodules, cavitation, pleural effusion and hilar adenopathy have been reported [118]. Culture of expectorated sputum samples can be positive, but higher yields are obtained using bronchoscopic sampling. Serum cryptococcal antigen is positive in patients with disseminated crytococcosis, but can be negative in patients with isolated pulmonary disease. Evaluation of patients with pulmonary cryptococcosis should include investigation for disseminated infection with serum and cerebrospinal fluid cryptococcal antigen testing, as well as blood and cerebrospinal fluid cultures [119]. Up to $75 \%$ of patients with HIV-associated cryptococcosis have positive blood cultures.

The recommended treatment is amphotericin B deoxycholate combined with flucytosine for $\geqslant 2$ weeks followed by fluconazol. Secondary prophylaxis can be discontinued when there is a sustained increase (e.g. $>6$ months) of CD4 lymphocyte counts $\geqslant 200$ cells per $\mathrm{mm}^{3}$ after HAART [50].

Invasive aspergillosis is a relatively uncommon infection in patients with AIDS, with an overall incidence of $\sim 1 \%$ in the earlier years of the HIV epidemic [120]. The infection is less common after the advent of HAART [121, 122]. Aspergillosis most often occurs in patients who have CD4 cell counts $<100$ cells per $\mathrm{mm}^{3}$. Risk factors for the development of invasive disease are neutropenia and corticosteroid use, but these are often absent. The lung is the most common site of Aspergillus infection and two forms of pulmonary disease have been described in HIVinfected patients: invasive pulmonary disease, which accounts for
$>80 \%$ of cases, and tracheobronchial disease. The chest radiograph might demonstrate a diffuse, focal or cavitary infiltrate in patients with invasive pneumonia; the "halo" and the "air

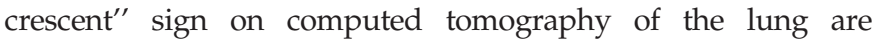
suggestive of invasive disease. Several forms of tracheobronchitis have been described: obstructive bronchial aspergillosis, ulcerative tracheobronchitis and pseudomembranous tracheobronchitis. The chest radiograph may be normal or may reveal areas of atelectasis or parenchymal infiltration [120]. The diagnosis of definite invasive aspergillosis requires the detection of Aspergillus in cultures and histological evidence of tissue invasion. Aspergillus is ubiquitous, and its presence in nasopharyngeal secretions, sputum and BAL fluid may represent contamination or colonisation. Newer tests based on circulating fungal antigen (mainly the serum galactomannan antigen) have been employed to diagnose aspergillosis, but they have not been formally evaluated in patients with HIV infection. Treatment of aspergillosis in the HIV-infected population has not been examined systematically but, currently, voriconazole is considered the drug of choice for the treatment of invasive aspergillosis [123]. Lipid formulations of amphotericin B, echinocandins and posaconazol are alternatives. The length of therapy is not established but should continue at least until the CD4 count is $>200$ cells per $\mathrm{mm}^{3}$ and there is evidence of clinical response [50]. No data are available to establish a recommendation of therapy among patients who have successfully completed an initial course of treatment [50].

\section{Viral infections}

Respiratory viruses might contribute to pulmonary complications in HIV-infected patients, although information on the causes, risk factors and outcomes of respiratory viral infection in these patients is very scarce [124-126]. Moreover, the respective role of each agent could vary according to the population and the season studied [124, 127, 128]. Influenza is a common cause of respiratory illness in adults with HIV, although HAART seems to have reduced the number of patients treated for influenza in hospital [124, 129]. People with HIV are usually considered to be at increased risk from serious influenza-related complications, mostly based on studies carried out in the pre-HAART era [130]. However, recent studies have shown that HIV patients with pandemic influenza virus A/H1N1 infection who are well controlled on HAART had a similar clinical outcome to that of non-HIV patients [131, 132]. Annual influenza vaccination for adults infected with HIV is recommended by the CDC and the IDSA, although this recommendation has not received universal support [50]. The only clinical trial showed a $20 \%$ absolute reduction in the risk of respiratory symptoms and $100 \%$ protection against laboratory-confirmed symptomatic influenza among HIV-infected patients receiving the influenza vaccine compared with those receiving placebo [133]. Two systematic reviews concluded that influenza vaccination of adults infected with HIV might be effective despite variable antibody responses $[134,135]$. However, more information is needed to confirm how effective and safe vaccination is in these patients, particularly among those with very low CD4 counts [129]. Recently, the role of human metapneumovirus infection in adults with HIV infection has been described [126].

The clinical significance of cytomegalovirus (CMV) as a pulmonary pathogen in HIV-infected patients is often unclear. 
Retinitis and gastrointestinal disease are the most common manifestations, but pneumonitis is infrequent. CMV as a sole cause of pneumonia is not common until the CD4 cell count is $<50$ cells per $\mathrm{mm}^{3}$. A particular problem is posed by the coexistence of CMV with other pathogens found in BAL fluid, particularly $P$. jirovecii. To date, the role of $\mathrm{CMV}$ in this coexistence is not clear. Criteria for establishing that CMV is the cause of pneumonia are difficult to create. A diagnosis of CMV pneumonitis could be made in the setting of pulmonary interstitial infiltrates, identification of CMV inclusion bodies and specific cytopathic changes in the lungs, and the absence of other pathogens that are more commonly associated with pneumonitis in this population.

\section{Parasitic infections}

Parasitic infections result in substantial morbidity and mortality among HIV patients worldwide. Responsible organisms include Toxoplasma gondii, Strongyloides stercoralis, Cryptosporidium and Microsporidium.

T. gondii is the most frequent parasitic pneumonia seen in persons with HIV infection. Although encephalitis is overwhelmingly the most common manifestation of $T$. gondii, pneumonitis has become its second most common presentation [136, 137]. Active pulmonary toxoplasmosis does not usually occur until the CD4 count falls below 100 cells per $\mathrm{mm}^{3}$. Pulmonary toxoplasmosis may be clinically indistinguishable from PCP, TB, cryptococcosis or histoplasmosis. The chest radiograph usually reveals bilateral infiltrates, either fine reticulonodular infiltrates indistinguishable from PCP or coarser nodular pattern similar to that seen with TB or fungal pneumonias. Most cases of T. gondii disease are due to reactivation of latent infection. Consequently, almost all persons with toxoplasmosis are positive for serum Toxoplasma immunoglobulin $G$ antibody. Its absence makes the diagnosis of Toxoplasma pneumonia unlikely. The diagnosis of pulmonary toxoplasmosis is usually established by bronchoscopy with BAL, but its sensitivity and specificity are unknown.

There are a few case reports of pulmonary disease due to $S$. stercoralis, Cryptosporidium and Microsporidium, which occur in the setting of disseminated infection.

\section{Polymicrobial aetiology}

Pulmonary infections with more than one pathogen are common in HIV-infected patients, particularly in cases of advanced immunosuppression. In one study, the rate of polymicrobial infections was $\sim 9 \%$ of all pulmonary infiltrates [14]. Several studies have shown that any of the aetiological microorganisms identified were not initially suspected [14, 138]. This underlines the importance of achieving an aetiological diagnosis.

\section{DIAGNOSIS OF PULMONARY INFECTIONS IN PATIENTS WITH HIV INFECTION}

There is no consensus on a diagnostic algorithm of pulmonary infections in HIV patients. Some investigators have recommended an empirical approach based on clinical features and local epidemiology. They have also suggested that diagnostic techniques should only be considered for patients in whom empirical therapy fails [23]. Other authors think that the aim should always be to achieve an aetiological diagnosis by means of noninvasive specimens initially, followed by invasive techniques if these specimens are non-diagnostic [139]. A study showed that not having an aetiological diagnosis was associated with increased mortality [14]. In this way, it is important to remember that while it is always appealing to make a single diagnosis and initiate therapy, multiple simultaneous processes are common in HIV patients, particularly in those with a lower CD4 count [14, 97]. The occurrence of multiple simultaneous infections can delay and complicate appropriate therapy. Additionally, it must be taken into account that the differential diagnosis of pulmonary infiltrates in HIV patients includes both infectious and noninfectious conditions.

The initial approach to the diagnosis of pulmonary infections in HIV-infected patients begins with an adequate clinical history and physical examination. Since the differential diagnosis is broad, historical clues may be useful in narrowing the possibilities, and selecting initial empiric therapy.

\section{Clinical assessment}

The history should include information on: 1) current and previous employment, hobbies and habits (risk of $R$. equi in horse breeders and Cryptococcus neoformans in cavers and pigeon breeders); 2) residence in or travel to regions prevalent for TB or endemic fungi; 3) assessment of any possible exposure to active TB; 4) use of intravenous drugs; 5) prolonged duration of neutropenia (higher risk for Gram-negative infection or Aspergillus); 6) history of prior infections and antimicrobial exposure (risk of reactivation of old infections when CD4 cell count decreases and higher risk for organisms with resistance to antimicrobials used previously); 7) current use of opportunistic infection prophylaxis; 8) history and current use of ART; and 9) more recent CD4 cell count (see below). The presenting complaints and the duration of these complains should be obtained.

The physical examination should look for signs suggesting extrapulmonary or disseminated disease that may tie together the respiratory complaints and pulmonary findings. The skin can show manifestations of pulmonary-associated bacterial, fungal or viral infections. Examination of the fundus and optic disc may suggest the presence of viral (CMV), fungal or mycobacterial infection (mainly TB).

\section{CD4 count}

The sequence of pulmonary complications occurring in HIVinfected persons parallels the depletion of CD4 lymphocytes. As a result, the CD4 count provides information about the pulmonary diseases to which the patient is susceptible. However, the CD4 Tlymphocyte count measured during the acute stage of infections should not be used to determine the stage of HIV disease, as decreases in the CD4 cell count have been noted in various infections [140].

Bacterial pneumonia (especially S. pneumoniae) and TB can occur early in the course of HIV infection, when the CD4 count is $>500$ cells per $\mathrm{mm}^{3}$, although both appear more frequently as immune function declines.

PCP and other fungal disease (cryptococcosis and endemic fungal infections, usually disseminated), disseminated nontuberculous mycobacterioses with pulmonary involvement, toxoplasmosis and CMV infections generally occur when the CD4 counts are $<200$ cells per $\mathrm{mm}^{3}$. 


\section{Imaging studies}

Plain chest radiography is an appropriate initial imaging study for a HIV-infected patient with suspected pulmonary infection. Any new abnormalities, including pulmonary infiltrates, pleural effusions and/or intrathoracic adenopathy, should be pursued for a definite diagnosis. Certain radiographic patterns as well as time of appearance and rate of progression can assist in the initial diagnosis (table 2, fig. 1) [141].

Chest computed tomography scans have become an important part of the diagnostic evaluation of HIV patients suspected to have pulmonary infections as they are more sensitive than plain chest radiographs in the detection of early interstitial lung disease, lymphadenopathy and nodules.

\section{Specific diagnostic tests}

The high overall yield of the microbiological analysis of spontaneously expectorated sputum sample $(>50 \%)$ in HIVinfected patients with pulmonary infiltrates is worth mentioning [14]. In the case of bacterial pneumonia, the yield of sputum culture ranges from $35 \%$ to $60 \%$ [14, 142]. Additionally, its availability and ease of performance highlight the usefulness of this technique [142]. Moreover, the need for performing systematic sputum cultures for mycobacteria in these patients should be considered.

Induced sputum is not superior to a good expectorated sample for diagnosing pulmonary TB, but it is helpful in patients who are suspected of having TB and are unable to produce sputum [143, 144]. Induced sputum, if positive, is diagnostic for PCP. The value of sputum induction in the setting of other pulmonary infections is unknown.
The diagnostic yield of blood cultures is high in bacterial pneumonias (mainly pneumococcal and $H$. influenzae pneumonias) among HIV-infected persons. Additionally, cultures of blood for $H$. capsulatum and mycobacteria may provide a definitive diagnosis; the frequency of positive results is inversely related to the CD4 count [145].

Antigen and antibody testing are generally of little value in the diagnosis of acute infections in the HIV-infected host. Notable exceptions include assays designed to detect Histoplasma polysaccharide antigen and cryptococcal antigen. Histoplasma antigen can be detected in the urine of $90 \%$ of patients with disseminated infections, and in $75 \%$ of those with diffuse acute pulmonary histoplasmosis [146]. The sensitivity is highest when urine and serum are tested. The serum cryptococcal antigen is less likely to be positive in localised cryptococcal pneumonia compared to disseminated cryptococcosis. The assay has excellent specificity. Histoplasma and cryptococcal antigen may also be helpful in evaluating response or therapy.

Another noninvasive test that probably has an important diagnostic role is the detection of pneumococcal antigen in urine. There are no specific studies in HIV-infected patients, but the results obtained in the general population suggest a probable usefulness in this group.

The absence of diagnosis of atypical pneumonias (different from Legionella pneumophila) in different series suggests that the routine serological analysis for diagnosis of these aetiological agents is probably not necessary in the majority of cases.

Because of its high yield and low complication rate, fibreoptic bronchoscopy remains the procedure of choice for diagnosing

TABLE 2 Common radiographical appearances of pulmonary infections in HIV patients

\begin{tabular}{|c|c|c|}
\hline Chest radiograph or $\mathrm{CT}$ abnormality & Acute or subacute onset & Chronic onset \\
\hline Focal consolidation & Legionellosis & Nocardiosis \\
\hline \multirow[t]{3}{*}{ Diffuse interstitial infiltrate } & Pneumocystis jirovecii & Mycobacteriosis \\
\hline & Bacteria, especially Haemophilus influenzae & Fungal pneumonia, especially cryptococcal \\
\hline & (influenza, CMV) & Toxoplasmosis \\
\hline \multirow{2}{*}{ Nodules } & Fungi (cryptococosis, aspergillosis) & Fungi \\
\hline & Bacteria & \\
\hline \multirow[t]{2}{*}{ Adenopathy } & Tuberculosis & Mycobacteriosis \\
\hline & & Endemic fungal infections \\
\hline \multirow[t]{2}{*}{ Cavitary infiltrate } & Tuberculosis & Mycobacteriosis \\
\hline & Legionellosis & \\
\hline \multirow[t]{3}{*}{ Pleural effusion } & Pyogenic bacteria & Fungi \\
\hline & Fungi & Nocardiosis \\
\hline & Tuberculosis & \\
\hline Pneumothorax & Pneumocystis jirovecii & \\
\hline
\end{tabular}

CT: computed tomography; CMV: cytomegalovirus; IDU: intravenous drug users. Patients with acute, subacute or chronic onset have $<1$ week, $1-4$ weeks or $>4$ weeks of symptoms, respectively. 


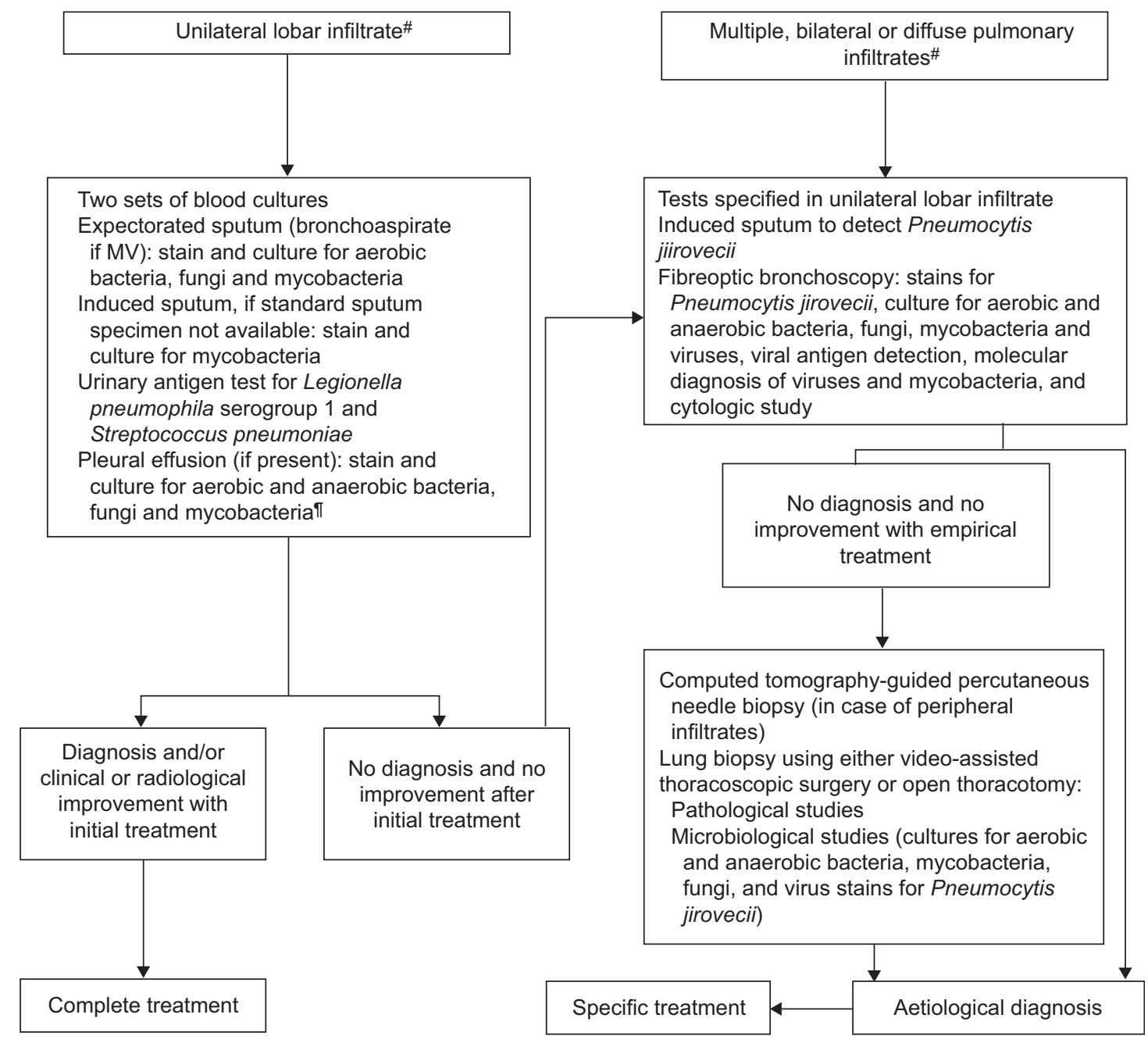

FIGURE 1. Diagnostic algorithm of pulmonary infiltrates in HIV-infected patients. MV: mechanical ventilation. * : in patients with a known or suspected CD4 cell count $<200$ cells per $\mathrm{mm}^{3}$, serum cryptococcal antigen, and blood and urine cultures for Mycobacterium can be useful; " : the determination of the adenosine deaminase can be useful for the diagnosis of pleural tuberculosis.

many pulmonary diseases in HIV-infected patients. In one study, this test achieved aetiological diagnosis in $56 \%$ of cases of pulmonary infiltrates [14]. The infections most commonly diagnosed using bronchoscopy included infections caused by $P$. jirovecii and mycobacterial, fungal and viral pathogens. Fibreoptic bronchoscopy is rarely performed in HIV-infected patients for the diagnosis of bacterial pneumonia. In these cases, to circumvent contamination from the upper airways, a double-lumen catheter system or a protected BAL is recommended. Semi-quantitative cultures of the collected specimens should be performed. Any antibiotic usage before the bronchoscopic procedure markedly decreases its sensitivity.

Transthoracic needle aspiration using computed tomography guidance has a high yield in diagnosing the cause of peripheral nodules and localised infiltrates; the yield is much lower in patients with diffuse disease.

Surgical lung biopsy, performed by means of thoracotomy or video-assisted thoracoscopic surgery, remains the procedure with the greatest sensitivity in the diagnosis of parenchymal lung disease.

\section{Diagnostic algorithm}

A possible diagnostic algorithm for HIV-infected patients with pulmonary infiltrates is shown in figure 1 . However, more studies are needed in order to establish the best diagnostic algorithm for these patients, which should take into account geographic differences in epidemiology.

\section{ART IN THE MANAGEMENT OF HIV-INFECTED PATIENTS WITH PULMONARY INFECTIONS}

\section{Initiation of ART in ART-naïve patients with a pulmonary infection}

Clinicians treating HIV-infected patients often have to consider when to initiate ART in ART-naïve persons with a recently diagnosed pulmonary infection. Initiation of early ART is associated with the risk of IRIS, drug interactions and a high pill burden, but deferral risks advancing immunosuppression and mortality. Initiation of ART in patients with TB has been discussed previously in the TB and other mycobacteriosis section. A recent clinical trial of when to initiate ART for patients with active opportunistic infections (excluding TB) showed that early initiation (within 14 days of starting therapy for the opportunistic 
infection) reduced death or AIDS progression by 50\% compared with beginning ART after the completion of opportunistic infection treatment [147]. The most common entry of opportunistic infection in this trial was PCP $(63 \%)$, followed by bacterial infections (12\%). It was concluded that additional studies are required for other infections [147]. Actually, a more recent study cautions that very early administration of ART in patients with cryptococcal meningitis (within $72 \mathrm{~h}$ after diagnosis) can be associated with increased mortality [148]. Based on these data, and according to current guidelines, it can be recommended for most patients with pulmonary opportunistic infections that ART should be initiated within approximately 2 weeks after initiation of infection treatment [50,149-151]. In patients with pulmonary cryptococcosis and meningitis, a short delay may be considered before initiating ART treatment [150]. Consideration must be given to the potential for drug interactions among therapies for opportunistic infections and ART.

\section{Management in patients with pulmonary infections receiving $A R T$}

When the infection occurs within 12 weeks of starting ART, many cases can represent unmasking IRISs; treatment of the infection should be started and ART should be continued [50]. When the infection occurs $>12$ weeks after initiation of ART, despite complete virological suppression, therapy for the infection should be initiated and ART should be continued; if the CD4 responses has been suboptimal, modification of the ART regimen could be considered [50]. When the infection occurs in the setting of virological failure, infection therapy should be started and the ART regimen should be modified to achieve better virological control [50].

\section{INTENSIVE CARE OF HIV-INFECTED PATIENTS WITH PULMONARY INFECTIONS}

Since the beginning of the AIDS epidemic, respiratory failure has been the most common indication for intensive care unit (ICU) admission among patients with HIV infection [152]. In the early years of the HIV pandemic, respiratory failure due to PCP was by far the most common disorder that prompted ICU admission and outcomes were uniformly dismal [153, 154]. ICU care was perceived as futile by physicians. Since then, the proportion of ICU admissions caused by respiratory failure has declined, but respiratory failure remains the most common indication for ICU admission in the current era of HAART [152, 155]; bacterial pneumonia and PCP are the leading causes of acute respiratory failure, but the proportion of PCP has decreased [155-157]. Survival for critically ill HIV-infected patients continues to improve in the current era and could be comparable to the overall survival in non-HIV ICU patients [155, 158]. Consequently, clinicians should no longer consider HIV infection as the driving factor for determining outcome in patients with HIV infection and respiratory failure [159, 160].

\section{PROGNOSIS OF HIV-INFECTED PATIENTS WITH PULMONARY INFECTIONS}

Overall, studies analysing prognostic factors of pulmonary infections in HIV patients are scarce. In a pre-HAART series of patients with pulmonary infections requiring ICU admission, PCP and mechanical ventilation were associated with higher mortality [153]. A study of patients with HIV infection and pulmonary infiltrates showed that not having an aetiological diagnosis was independently associated with higher mortality [14]. This is a factor of special concern, since it focuses on the need for an improvement in the diagnostic yield of techniques and optimising the diagnostic algorithm.

Most investigations have focused on PCP, and a mortality of 10 $30 \%$ has been reported $[14,15,68,161]$. There has been little change in mortality over the past 20 yrs [14, 161]. The degree of hypoxaemia at presentation is strongly related to the prognosis of PCP: the case fatality rate is $<10 \%$ in patients with mild to moderate disease, whereas it is $>20 \%$ in patients with marked abnormalities in gas exchange [162, 163]. Other factors include older age, presence of comorbidities, malnourishment, injection drug use, prior episodes of PCP, high LDH levels, marked neutrophilia in BAL, low haemoglobin level and high bilirubin level at hospital admission, the presence of cytomegalovirus in BAL fluid and a CD4 count $<50$ cells per $\mathrm{mm}^{3}[14,68,161,164]$. Improved survival has been described in the era of HAART among the subgroup of patients with severe PCP admitted to the ICU. Whether improved outcome is attributable to the direct effects of HAART or to general improvements in ICU care (in particular, protective ventilator strategies) remains unclear [161].

Previous studies have indicated a variable mortality (5-30\%) for HIV-associated bacterial pneumonia, although most of them range from $10 \%$ to $15 \%[12,14,29]$. The rate of associated mortality in a post-HAART series was lower than previously reported $(3.4 \%)$, which could be related to a lower incidence of pneumonia due to enterobacteriaceae and $P$. aeruginosa (associated with a higher mortality in previous studies) and a greater percentage of patients with higher levels of CD4 counts [14, 15]. Described predicting factors of higher mortality are a Karnofsky score of $\leqslant 50$, neutropenia, a CD4 cell count $<100$ cells per $\mathrm{mm}^{3}$, a partial pressure of oxygen $<70 \mathrm{mmHg}$, the presence of shock and radiographic progression of disease $[165,166]$. In many studies, rates of bacterial pneumonia-associated mortality are not increased in HIV-infected patients compared with those in control subjects $[12,167]$. However, these case-fatality proportions are difficult to compare since pneumonia in the absence of HIV infection often occurs in adults significantly older than those with HIV infection and with different comorbidities. Actually, results of different studies do not agree in this issue, and two recent studies showed bacterial pneumonia increased mortality risk in HIV-infected versus HIV-uninfected patients [19, 168].

\section{SUPPORT STATEMENT}

During 2011, J. M. Miro received an INT10/219 Research Intensification Grant (I3SNS and PRICS programmes) from the Instituto de Salud Carlos III, Madrid, Spain, and the Dept de Salut de la Generalitat de Catalunya, Barcelona, Spain.

\section{STATEMENT OF INTEREST}

None declared.

\section{REFERENCES}

1 Centers for Disease Control and Prevention (CDC). Pneumocystis pneumonia - Los Angeles. MMWR Morb Mortal Wkly Rep 1981; 30: 250-252.

2 Global report: UNAIDS report on the global AIDS epidemic 2010. www.unaids.org/globalreport/documents/20101123_GlobalReport _full_en.pdf Date last accessed: July 7, 2011. 
3 Grubb JR, Moorman AC, Baker RK, et al. The changing spectrum of pulmonary disease in patients with HIV infection on antiretroviral therapy. AIDS 2006; 20: 1095-1107.

4 Torres RA, Barr M. Impact of combination therapy for HIV infection on inpatient census. N Engl J Med 1997; 33: 1531-1532.

5 Sobrino-Vegas P, García-San Miguel L, Caro-Murillo AM, et al. Delayed diagnosis of HIV infection in a multicenter cohort: prevalence, risk factors, response to HAART and impact on mortality. Curr HIV Res 2009; 7: 224-230.

6 Mugavero MJ. Improving engagement in HIV care: what can we do? Top HIV Med 2008; 16: 156-161.

7 Afessa B, Greaves W, Gren W, et al. Autopsy findings in HIVinfected inner city patients. J Acquir Immune Defic Syndr 1992; 5: 132-136

8 Masliah E, DeTeresa RM, Mallory ME, et al. Changes in pathological findings at autopsy in AIDS cases for the last 15 years. AIDS 2000; 14: 69-74.

9 Murray JF, Garay SM, Hopewell PC, et al. NHLBI workshop summary. Pulmonary complications of the acquired immunodeficiency syndrome: an update. Report of the second National Heart, Lung, and Blood Institute workshop. Am Rev Respir Dis 1987; 135: 504-509.

10 Meduri GU, Stein DS. Pulmonary manifestations of acquired immunodeficiency syndrome. Clin Infect Dis 1992; 14: 98-113.

11 Miller R. HIV-associated respiratory diseases. Lancet 1996; 348: 307-312.

12 Feikin DR, Feldman C, Schuchat A, et al. Global strategies to prevent bacterial pneumonia in adults with HIV disease. Lancet Infect Dis 2004; 4: 445-455.

13 Lazarous DG, O'Donnell AE. Pulmonary infections in the HIVinfected patient in the era of highly active antiretroviral therapy: an update. Curr Infect Dis Rep 2007; 9: 228-232.

14 Benito N, Rañó A, Moreno A, et al. Pulmonary infiltrates in HIVinfected patients in the highly active antiretroviral therapy in Spain. J Acquir Immune Defic Syndr 2001; 27: 35-43.

15 Benito N, Moreno A, Filella X, et al. Inflammatory responses in blood samples of human immunodeficiency virus infected patients with pulmonary infections. Clin Diagn Lab Immunol 2004; 11: 608-614.

16 Whalen C, Horsburgh CR, Hom D, et al. Accelerated course of human immunodeficiency virus infection after tuberculosis. Am J Respir Crit Care Med 1995; 151: 129-135.

17 Osmond DH, Chin DP, Glassroth J, et al. Impact of bacterial pneumonia and Pneumocystis carinii pneumonia on human immunodeficiency virus disease progression. Clin Infect Dis 1999; 29: 536-543.

18 Morris AM, Huang L, Bacchetti P, et al. Permanent declines in pulmonary function following pneumonia in human immunodeficiency virus-infected persons. The Pulmonary Complications of HIV Infection Study Group. Am J Respir Crit Care Med 2000; 162: 612-616.

19 Kohli R, Lo Y, Homel P, et al. Bacterial pneumonia, HIV therapy, and disease progression among HIV-infected women in the HIV epidemiologic research (HER) study. Clin Infect Dis 2006; 43: 90-98.

20 Del Amo J, Perez-Hoyos S, Hernández Aguado I, et al. Impact of tuberculosis on HIV disease progression in persons with welldocumented time of HIV seroconversion. J Acquir Immune Defic Syndr 2003; 33: 184-190.

21 Wallace JM, Hansen NI, Lavange L, et al. Respiratory disease trends in the pulmonary complications of HIV infection study cohort. Am J Respir Crit Care Med 1997; 155: 72-80.

22 Wolff AJ, O'Donnell AE. Pulmonary manifestations of HIV infection in the era of highly active antiretroviral therapy. Chest 2001; 120: 1888-1893.

23 Murray F. Pulmonary complications of HIV-1 infection among adults living in Sub-Saharan Africa. Int J Tuberc Lung Dis 2005; 9 : 826-835.
24 Daley CL, Mugusi F, Chen LL, et al. Pulmonary complications of HIV infection in Dar es Salaam, Tanzania. Role of bronchoscopy and bronchoalveolar lavage. Am J Respir Crit Care Med 1996; 154: 105-110.

25 Van Oosterhout JJ, Laufer MK, Perez MA, et al. Pneumocystis pneumonia in HIV-positive adults, Malawi. Emerg Infect Dis 2007; 13: 325-328.

26 Fisk DT, Meshnick S, Kazanjian PH. Pneumocystis carinii pneumonia in patients in the developing world who have acquired immunodeficiency syndrome. Clin Infect Dis 2003; 36: 70-78.

27 Serraino D, Puro V, Boumis E, et al. Epidemiological aspects of major opportunistic infections of the respiratory tract in persons with AIDS: Europe, 1993-2000. AIDS 2003; 17: 2109-2116.

28 Rosen MJ. Pulmonary complications of HIV infection. Respirology 2008; 13: 181-190.

29 Hirschtick RE, Glassroth J, Jordan MC, et al. Bacterial pneumonia in persons infected with the human immunodeficiency virus. N Engl J Med 1995; 333: 845-851.

30 Davis JL, Fei M, Huang L. Respiratory infection complicating HIV infection. Curr Opin Infect Dis 2008; 21: 184-190.

31 Crothers K, Huang L, Goulet JL, et al. HIV infection and risk for incident pulmonary diseases in the combination antiretroviral therapy era. Am J Respir Crit Care Med 2011; 183: 388-395.

32 Benito-Hernández N, Moreno-Camacho A, Gatell-Artigas JM. Complicaciones infecciosas pulmonares en los pacientes con infección por el virus de la inmunodeficiencia humana en la era del tratamiento antirretroviral de gran actividad en España [Infectious complications in HIV-infected patients in the high by active antiretroviral therapy era in Spain]. Med Clin (Barc) 2005; 125: 548-555.

33 Gordin FM, Roediger MP, Girard PM, et al. Pneumonia in HIVinfected persons: increased risk with cigarette smoking and treatment interruption. Am J Respir Crit Care Med 2008; 178: 630-636.

34 Miquez-Burbano MJ, Burbano X, Ashkin D, et al. Impact of tobacco use on the development of opportunistic respiratory infections in HIV seropositive patients on antirretroviral therapy. Addict Biol 2003; 8: 39-43.

35 Pett SL, Carey C, Lin E, et al. Predictors of bacterial pneumonia in evaluation of subcutaneous interleukin-2 in a randomized international trial (ESPRIT). HIV Med 2011; 12: 219-227.

36 De Gaetano Donati K, Bertagnolio S, Tumbarello M, et al. Effect of highly active antirretroviral therapy on the incidence of bacterial pneumonia in HIV-infected subjects. Int J Antimicrob Agents 2000; 16: 357-360.

37 Sullivan JH, Moore RD, Keruly JC, et al. Effect of antiretroviral therapy on the incidence of bacterial pneumonia in patients with advanced HIV infection. Am J Respir Crit Care Med 2000; 162: 64-67.

38 De Gaetano Donati K, Tumbarello M, Tacconelli E, et al. Impact of highly active antiretroviral therapy (HAART) on the incidence of bacterial infections in HIV infected subjects. J Chemother 2003; 16: 60-65

39 Saindou M, Chidiac C, Miailhes $\mathrm{P}$, et al. Pneumococcal pneumonia in HIV-infected patients by antiretroviral therapy periods. HIV Med 2008; 9: 203-207.

40 French N, Nakiyingi J, Carpenter LM, et al. 23-valent pneumococcal polysaccharide vaccine in HIV-1-infected Ugandan adults: double-blind, randomised and placebo controlled trial. Lancet 2000; 355: 2106-2111.

41 Watera C, Nakiyingi J, Miiro G, et al. 23-valent pneumococcal polysaccharide vaccine in HIV-infected Ugandan adults: 6-year follow-up of a clinical trial cohort. AIDS 2004; 18: 1210-1213.

42 Gebo KA, Moore RD, Keruly JC, et al. Risk factors for pneumococcal disease in human immunodeficiency virusinfected patients. J Infect Dis 1996; 173: 857-862.

43 Guerrero M, Kruger S, Saitoh A, et al. Pneumonia in HIVinfected patients: a case-control survey of factors involved in risk and prevention. AIDS 1999; 13: 1971-1975. 
44 Breiman RF, Keller DW, Phelan MA, et al. Evaluation of effectiveness of the 23-valent pneumococcal capsular polysaccharide vaccine for HIV-infected patients. Arch Intern Med 2000; 160: 2633-2638.

45 Hung CC, Chen MY, Hsieh SM, et al. Clinical experience of the 23-valent capsular polysaccharide pneumococcal vaccination in HIV-1-infected patients receiving highly active antiretroviral therapy: a prospective observational study. Vaccine 2004; 22: 2006-2012.

46 Peñaranda M, Falcó V, Payeras A, et al. Effectiveness of polysaccharide pneumococcal vaccine in HIV-infected patients: a case-control study. Clin Infect Dis 2007; 45: e82-e87.

47 Rodriguez-Barradas MC, Goulet J, Brown S, et al. Impact of pneumococcal vaccination on the incidence of pneumonia by HIV infection status among patients enrolled in the veterans aging cohort 5-site study. Clin Infect Dis 2008; 46: 1093-1100.

48 Grau I, Pallares R, Tubau F, et al. Epidemiologic changes in bacteremic pneumococcal disease in patients with human immunodeficiency virus in the era of highly active antiretroviral therapy. Arch Intern Med 2005; 165: 1533-1540.

49 Centers for Disease Control and Prevention, Infectious Diseases Society of America. 1999 USPHS/IDSA guidelines for the prevention of opportunistic infections in people infected with human immunodeficiency virus. MMWR Recomm Rep 1999; 48: $1-66$.

50 Kaplan JE, Benson C, Holmes KH, et al. Guidelines for prevention and treatment of opportunistic infections in HIVinfected adults and adolescents: recommendations from CDC, the National Institutes of Health, and the HIV Medicine Association of the Infectious Diseases Society of America. MMWR Recomm Rep 2009; 58: 1-207.

51 Klugman K, Madhi S, Huebner R, et al. A trial of a 9-valent pneumococcal conjugate vaccine in children with and those without HIV infection. N Engl J Med 2003; 349: 1341-1348.

52 French N, Gordon SB, Mwalukomo T, et al. A trial of a 7-valent pneumococcal conjugate vaccine in HIV-infected adults. $N$ Engl J Med 2010; 362: 812-822.

53 Cordero E, Pachón J, Rivero A, et al. Haemophilus influenzae pneumonia in human immunodeficiency virus-infected patients. Clin Infect Dis 2000; 30: 461-465.

54 Afessa B, Green B. Bacterial pneumonia in hospitalized patients with HIV infection: the Pulmonary Complications, ICU Support, and Prognostic Factors of Hospitalized Patients with HIV (PIP) Study. Chest 2000; 117: 1017-1022.

55 Levine SJ, White DA, Fels AO. The incidence and significance of Staphylococcus aureus in respiratory cultures from patients infected with the human immunodeficiency virus. Am Rev Respir Dis 1990; 141: 89-93.

56 Tumbarello M, Tacconelli E, de Gaetano Doneti K, et al. Nosocomial bacterial pneumonia in human immunodeficiency virus infected subjects: incidence, risk factors and outcome. Eur Respir J 2001; 17: 636-640.

57 Pedro-Botet ML, Sabrià M, Sopena N, et al. Legionnaires diseases and HIV infection. Chest 2003; 124: 543-547.

58 Filice GA. Nocardiosis in persons with human immunodeficiency virus infection, transplant recipients, and large, geographically defined populations. J Lab Clin Med 2005; 145: 156-162.

59 Javaly K, Horowitz HW, Wormser GP. Nocardiosis in patients with human immunodeficiency virus infection. Report of 2 cases and review of the literature. Medicine (Baltimore) 1992; 71: 128-138.

60 Choukri F, Menotti J, Sarfati C, et al. Quantification and spread of Pneumocystis jirovecii in the surrounding air of patients with Pneumocystis pneumonia. Clin Infect Dis 2010; 51: 259-265.

61 Bartlett MS, Lee C. Airborne spread of Pneumocystis carinii. Clin Infect Dis 2010; 51: 266.
62 Morris A, Wei K, Afshar K, et al. Epidemiology and clinical significance of Pneumocystis colonization. J Infect Dis 2008; 197: 10-17.

63 Chien SM, Rawji M, Mintz S, et al. Changes in hospital admissions pattern in patients with human immunodeficiency virus infection in the era of Pneumocystis carinii prophilaxis. Chest 1992; 102: 1035-1039.

64 Huang L, Quartin A, Jones D, et al. Intensive care of patients with HIV infection. N Engl J Med 2006; 355: 173-181.

65 Muñoz A, Schager LK, Bacellar H, et al. Trends in the incidence and outcomes defining acquired immunodeficiency syndrome (AIDS) in the multicenter AIDS cohort study: 1985-1999. Am J Epidem 1993; 137: 423-428.

66 Moore RD, Chaisson RE. Natural history of HIV infection in the era of combination antiretroviral therapy. AIDS 1999; 13: 1933-1942.

67 Furrer H, Egger M, Opravil M, et al. Discontinuation of primary prophylaxis against Pneumocystis carinii pneumonia in HIV-1infected adults treated with combination antiretroviral therapy. Swiss HIV Cohort Study. N Engl J Med 1999; 340: 1301-1306.

68 Pulvirenti J, Herrera P, Venkataraman P, et al. Pneumocystis carinii pneumonia in HIV-infected patients in the HAART era. AIDS Patient Care STDs 2003; 17: 261-265.

69 Selwyn PA, Pumerantz AS, Durante A, et al. Clinical predictors of Pneumocystis carinii pneumonia, bacterial pneumonia and tuberculosis in HIV-infected patients. AIDS 1998; 12: 885-893.

70 Hidalgo A, Falco V, Mauleon S, et al. Accuracy of high-resolution CT in distinguishing between Pneumocistis carinii pneumonia and non-Pneumocystis carinii pneumonia in AIDS patients. Eur Radiol 2003; 13: 1179-1184.

71 Gruden JF, Huang L, Turner J, et al. High-resolution CT in the evaluation of clinically suspected Pneumocystis carinii pneumonia in AIDS patients with normal, equivocal or non-specific radiographic findings. AJR Am J Roentgenol 1997; 169: 967-975.

72 Butt AA, Michaels S, Kissinger P. The association of serum lactate dehydrogenase level with selected opportunistic infections and HIV progression. Int J Infect Dis 2002; 6: 178-181.

73 Skelly MJ, Holzman RS, Merali S. S-adenosylmethionine levels in the diagnosis of Pneumocystis carinii pneumonia in patients with HIV infection. Clin Infect Dis 2008; 46: 467-471.

74 Sax PE, Komarow L, Finkelman MA, et al. Blood $(1 \rightarrow 3)-\beta-D-$ glucan as a diagnostic test for HIV-related Pneumocystis jirovecii pneumonia. Clin Infect Dis 2011; 53: 197-202.

75 Cruciani M, Marcati P, Malena M, et al. Meta-analysis of diagnostic procedures for Pneumocystis carinii pneumonia in HIV-1-infected patients. Eur Respir J 2002; 20: 982-989.

76 Turner D, Schwarz Y, Yust I. Induced sputum for diagnosing Pneumocystis carinii pneumonia in HIV patients: new data, new issues. Eur Respir J 2003; 21: 204-208.

77 Alvarez-Martínez MJ, Miró JM, Valls ME, et al. Sensitivity and specificity of nested and real-time PCR for the detection of Pneumocystis jiroveci in clinical specimens. Diag Microb Infect Dis 2006; 56: 153-160.

78 Roger PM, Vandenbos F, Pugliese P, et al. Persistence of Pneumocystis carinii after effective treatment of $P$. carinii pneumonia is not related to relapse or survival among patients infected with human immunodeficiency virus. Clin Infect Dis 1998; 26: 509-510.

79 Briel M, Bucher HC, Boscacci R, et al. Adjunctive corticosteroids for Pneumocystis jiroveci pneumonia in patients with HIVinfection. Cochrane Database Syst Rev 2006; 3: CD006150.

80 Valerio A, Tronconi E, Mazza F, et al. Genotyping of Pneumocystis jiroveci pneumonia in Italian AIDS patients. Clinical outcome is influenced by dihydropteroate synthase and not by internal transcribed spacer genotype. J Acquir Immune Defic Syndr 2007; 45: 521-528.

81 Alvarez-Martínez MJ, Moreno A, Miró JM, et al. Pneumocystis jirovecii pneumonia in Spanish HIV-infected patients in the 
combined antiretroviral therapy era: prevalence of dihydropteroate synthase mutations and prognostic factors of mortality. Diagn Microbiol Infect Dis 2008; 62: 34-43.

82 Alvarez-Martínez MJ, Miró JM, Valls ME, et al. Prevalence of dihydropteroate synthase genotypes before and after the introduction of combined antiretroviral therapy and their influence on the outcome of Pneumocystis pneumonia in HIV-1infected patients. Diagn Microbiol Infect Dis 2010; 68: 60-65.

83 López Bernaldo de Quirós JC, Miró JM, et al. A randomized trial of the discontinuation of primary and secondary prophylaxis against Pneumocystis carinii pneumonia after highly active antiretroviral therapy in patients with HIV infection. $N$ Engl $J$ Med 2001; 344: 159-167.

84 Opportunistic Infections Project Team of the Collaboration of Observational HIV Epidemiological Research in Europe (COHERE), Mocroft A, Reiss P, et al. Is it safe to discontinue primary Pneumocystis jiroveci pneumonia prophylaxis in patients with virologically suppressed HIV infection and a CD4 cell count $<200$ cells $/ \mu \mathrm{L}$ ? Clin Infect Dis 2010; 51: 611-619.

85 Swaminathan S, Padmapriyadarsini C, Narendran G. HIVassociated tuberculosis: clinical update. Clin Infect Dis 2010; 50: 1377-1386.

86 Treatment and care: unprecedented progress, remaining challenges. Chapter 5. http://data.unaids.org/pub/GlobalReport/ 2008/jc1510_2008_global_report_pp129_158_en.pdf Date last accessed: July 7, 2011.

87 Sonnenberg P, Glynn JR, Fielding K, et al. How soon after infection with HIV does the risk of tuberculosis start to increase? A retrospective cohort study in South African gold miners. J Infect Dis 2005; 191: 150.

88 DeRiemer K, Kawamura LM, Hopewell PC, et al. Quantitative impact of human immunodeficiency virus infection on tuberculosis dynamics. Am J Respir Crit Care Med 2007; 176: 936-944.

89 Lawn SD, Bekker LG, Wood R. How effectively does HAART restore immune responses to Mycobacterium tuberculosis? Implications for tuberculosis control. AIDS 2005; 19: 1113-1124.

90 Girardi E, Sabin CA, d'Arminio Monforte A, et al. Incidence of tuberculosis among HIV-infected patients receiving highly active antiretroviral therapy in Europe and North America. Clin Infect Dis 2005; 41: 1772.

91 Lawn SD, Badri M, Wood R. Tuberculosis among HIV-infected patients receiving HAART: long term incidence and risk factors in a South African cohort. AIDS 2005; 19: 2109-2116.

92 Havlir DV, Getahun H, Sann I, et al. Opportunities and challenges for HIV care in overlapping HIV and TB epidemics. JAMA 2008; 300: 423-430.

93 Lawn SD, Myer L, Edwards D, et al. Short-term and long-term risk of tuberculosis associated with CD4 cell recovery during antiretroviral therapy in South Africa. AIDS 2009; 23: 1717-1725.

94 Chaisson RE, Martinson NA. Tuberculosis in Africa - combating an HIV-driven crisis. N Engl J Med 2008; 358: 1089-1092.

95 Prendergast A, Tudor-Williams G, Jeena P, et al. International perspectives, progress, and future challenges of paediatric HIV infection. Lancet 2007; 370: 68-80.

96 Markowitz N, Hansen N, Hopewell PC, et al. Incidence of tuberculosis in the United States among HIV-infected persons. Ann Intern Med 1997; 126: 123-132.

97 Kirk O, Gatell JM, Mocroft A, et al. Infections with Mycobacterium tuberculosis and Mycobacterium avium among HIV-patients after the introduction of highly active antiretroviral therapy. Am J Respir Crit Care Med 2000; 162: 865-872.

98 Nahid P, Pai M, Hopewell PC. Advances in the diagnosis and treatment of tuberculosis. Proc Am Thorac Soc 2006; 3: 103-110.

99 Boehme CC, Nabeta P, Hillemann D, et al. Rapid molecular detection of tuberculosis and rifampin resistence. $N$ Engl J Med 2010; 363: 1005-1015.
100 Khan FA, Minion J, Pai M, et al. Treatment of active tuberculosis in HIV-coinfected patients: a systematic review and metaanalysis. Clin Infect Dis 2010; 50: 1288-1299.

101 Boulle A, Van Cutsem G, Cohen K, et al. Outcomes of nevirapine- and efavirenz-based antiretroviral therapy when coadministared with rifampin-based antitubercular therapy. JAMA 2008; 300: 530-539.

102 Abdool Karim SS, Naidoo K, Grobler A, et al. Timing of initiation of antiretroviral drugs during tuberculosis therapy. N Eng J Med 2010; 362: 697-706.

103 Blanc FX, Sok T, Laureillard D, et al. Earlier versus later start of antiretroviral therapy in HIV-infected adults with tuberculosis. N Engl J Med 2011; 365: 1471-1481.

104 Abdool Karim SS, Naidoo K, Padayatchi N, et al. Integration of antiretroviral therapy with tuberculosis treatment. $N$ Engl J Med 2011; 365: 1492-1501.

105 Havlir D, Ive P, Kendall M, et al. Turning of antiretroviral therapy for HIV-1 infection and tuberculosis. N Engl J Med 2011; 365: 1482-1491.

106 Meintjes G, Wilkinson RJ, Morroni C, et al. Randomized placebocontrolled trial of prednisone for paradoxical tuberculosisassociated immune reconstitution inflammatory syndrome. AIDS 2010; 24: 2381-2390.

107 World Health Organization. Antiretroviral therapy for HIV infections in adults and adolescents: recommendations for a public health approach. 2010 revision. Geneva, World Health Organization, 2010.

108 Centers of Diseases Control and Prevention. Tuberculosis. www cdc.gov/tb/TB_HIV_Drugs/default.htm. Date last accessed: July 7, 2011.

109 Sthephan C, Wolf T, Goetsch U, et al. Comparing QuantiFERONtuberculosis gold, T-SPOT tuberculosis and tuberculin skin test in HIV-infected individuals from a low prevalence tuberculosis country. AIDS 2008; 22: 2471-2479.

110 Smith RM, Cattamanchi A, Metcalfe J, et al. Systematic review of sensitivity of interferon-gamma release assays for detection of $M$. tuberculosis infection in HIV-infected patients. Am J Respir Crit Care Med 2010; 181: A2264.

111 World Health Organization. Guidelines for intensified tuberculosis case-finding and isoniazid preventive therapy for people living with HIV in resource-constrained settings. Geneva, World Health Organization, 2010.

112 Martinson NA, Barnes GL, Moulton LH, et al. New regimens to prevent tuberculosis in adults with HIV infection. $N$ Engl J Med 2011; 365: 11-20.

113 Woods CW, McRill C, Plikaytis BD, et al. Coccidioidomycosis in human immunodeficiency virus-infected persons in Arizona, 1994-1997: incidence, risk factors, and prevention. J Infect Dis 2000; 181: 1428-1434.

114 Benito N, Garcia Vazquez E, Blanco A, et al. Disseminated histoplasmosis in AIDS patients. A study of 2 cases and review of the Spanish literature. Enferm Infecc Microbiol Clin 1998; 7: 316-321.

115 Chapman SW, Dismukes WE, Proia LA, et al. Clinical practice guidelines for the management of blastomycosis: 2008 update by the Infectious Diseases Society of America. Clin Infect Dis 2008; 46: 1801-1812.

116 Goldman M, Zackin R, Fichtenbaum CJ, et al. Safety of discontinuation of maintenance therapy for disseminated histoplasmosis after immunologic response to antiretroviral therapy. Clin Infect Dis 2004; 38: 1485-1489.

117 Mirza SA, Phelan M, Rimland D, et al. The changing epidemiology of cryptococcosis: an update from population-based active surveillance in 2 large metropolitan areas, 1992-2000. Clin Infect Dis 2003; 36: 789-794.

118 Meyohas MC, Roux P, Bollens D, et al. Pulmonary cryptococcosis: localized and disseminated infections in 27 patients with AIDS. Clin Infect Dis 1995; 21: 628-633. 
119 Dromer F, Mathoulin-Pelissier S, Launay O, et al. Determinants of disease presentation and outcome during cryptococcosis: the CryptoA/D study. PLoS Med 2007; 4: e21.

120 Miller WT Jr, Sais GJ, Frank I, et al. Pulmonary aspergillosis in patients with AIDS. Clinical and radiographic correlations. Chest 1994; 105: 37-44.

121 Mylonakis E, Barlam TF, Flanigan T, et al. Pulmonary aspergillosis and invasive disease in AIDS: review of 342 cases. Chest 1998; 114: 251-262.

122 Holding KJ, Dworkin MS, Wan PC, et al. Aspergillosis among people infected with human immunodeficiency virus: incidence and survival. Clin Infect Dis 2000; 31: 1253-1257.

123 Walsh TJ, Anaissie EJ, Denning DW, et al. Treatment of aspergillosis: clinical practice guidelines of the Infectious Diseases Society of America. Clin Infect Dis 2008; 46: 327-360.

124 Garbino J, Inoubli S, Mossdorf E, et al. Respiratory viruses in HIV-infected patients with suspected respiratory opportunistic infection. AIDS 2008; 22: 701-705.

125 Perello R, Moreno A, Camps M, et al. Implicación de los virus respiratorios en la comunidad en pacientes infectados por el virus de la inmunodeficiencia humana [Human immunodeficiency virus-infected patients with community-acquired pneumonia: implication of respiratory viruses]. Enferm Infect Microbiol Clin 2008; 26: 85-87.

126 Klein MB, Yang H, DelBalso L, et al. Viral pathogens including human metapneumovirus are the primary cause of febrile respiratory illness in HIV-infected adults receiving antiretroviral therapy. J Infect Dis 2010; 201: 297-301.

127 Klein MB, Lu Y, Del Baso L, et al. Influenza virus infection is a primary cause of febrile respiratory illness in HIV-infected adults despite vaccination. Clin Infect Dis 2007; 45: 234-240.

128 Madhi SA, Ludewick H, Kuwanda L, et al. Seasonality, incidence, and repeat human metapneumovirus lower respiratory tract infections in an area with a high prevalence of human immunodeficiency virus type-1 infection. Pediatr Infect Dis J 2007; 26: 693-699.

129 Kunisaki KM, Janoff EN. Influenza in immunosuppressed populations: a review of infection frequency, morbidity, mortality, and vaccine responses. Lancet Infect Dis 2009; 9: 493-504.

130 Fiore AE, Uyeki TM, Broder K, et al. Prevention and control of influenza with vaccines: recommendations of the Advisory Committee on Immunization Practices (ACIP), 2010. MMWR Recomm Rep 2010; 59: 1-68.

131 Riera M, Payeras A, Marcos MA, et al. Clinical presentation and prognosis of the 2009 H1N1 influenza A infection in HIV-1infected patients: a Spanish multicenter study. AIDS 2010; 24: 2461-2467.

132 Martínez E, Marcos MA, Hoyo I, et al. Influenza A H1N1 in HIVinfected adults. HIV Med 2011; 12: 236-245.

133 Tasker SA, Treanor JJ, Paxton WB, et al. Efficacy of influenza vaccination in HIV-infected persons: a randomized, double-blind, placebo-controlled trial. Ann Intern Med 1999; 131: 430-433.

134 Atashili J, Kalilani L, Adimora AA. Efficacy and clinical effectiveness of influenza vaccines in HIV-infected individuals: a meta-analysis. BMC Infect Dis 2006; 6: 138.

135 Anema A, Mills E, Montaner J, et al. Efficacy of influenza vaccination in HIV-positive patients: a systematic review and meta-analysis. HIV Med 2008; 9: 57-61.

136 Gadea I, Cuenca M, Benito N, et al. Bronchoalveolar lavage for the diagnosis of disseminated toxoplasmosis in AIDS patients. Diagn Microbiol Infect Dis 1995; 22: 339-341.

137 Derouin F, Sarfati C, Beauvais B, et al. Prevalence of pulmonary toxoplasmosis in HIV-infected patients. AIDS 1990; 4: 1036.

138 Schleicher GK, Feldman C. Dual infection with Streptococcus pneumoniae and Mycobacterium tuberculosis in HIV-seropositive patients with community acquired pneumonia. Int J Tuberc Lung Dis 2003; 7: 1207-1208.
139 Narayanswami G, Salzman SH. Bronchoscopy in the human immunodeficiency virus-infected patient. Sem Respir Infect 2003; 18: 80-86.

140 Schleicher GK, Hopley MJ, Feldman C. CD4 T-lymphocyte subset counts in HIV-seropositive patients during the course of community-acquired pneumonia caused by Streptococcus pneumoniae. Clin Microbiol Infect 2004; 10: 587-589.

141 Gallant JE, Ko AH. Cavitary pulmonary lesions in patients infected with human immunodeficiency virus. Clin Infect Dis 1996; 22: 671-682.

142 Cordero E, Pachon J, Rivero A, et al. Usefulness of sputum culture for diagnosis of bacterial pneumonia in HIV-infected patients. Eur J Clin Microbiol Infect Dis 2002; 21: 362-367.

143 Anderson C, Inhaber N, Mengies D. Comparison of sputum induction with fiberoptic bronchoscopy in the diagnosis of tuberculosis. Am J Respir Crit Care Med 1995; 152: 1570-1574.

144 Conde MB, Soares SL, Mello FC, et al. Comparison of sputum induction with fiberoptic bronchoscopy in the diagnosis of tuberculosis: experience at an acquired immunodeficiency syndrome reference center in Rio de Janeiro, Brazil. Am J Respir Crit Care Med 2000; 162: 2238-2240.

145 Jones BE, Young SM, Antoniskis D, et al. Relationship of the manifestations of tuberculosis to CD4 counts in patients with human immunodeficiency virus infection. Am Rev Respir Dis 1993; 148: 1292-1297.

146 Wheat J. Histoplasmosis. Experience during outbreaks in Indianapolis and review of the literature. Medicine (Baltimore) 1997; 76: 339-354.

147 Zolopa AR, Andersen J, Komarow L, et al. Early antiretroviral therapy reduces AIDS progression/death in individuals with acute opportunistic infections: a multicenter randomized strategy trial. PLoS One 2009; 4: e5575.

148 Mazadzange AT, Ndhlovu CE, Takarinda K, et al. Early versus delayed initiation of antiretroviral therapy for concurrent HIV infection and cryptococcal meningitis in Sub-Saharan Africa. Clin Infect Dis 2010; 50: 1532-1538.

149 Panel de expertos de GESIDA, Plan Nacional sobre el Sida. Tratamiento de las infecciones oportunistas en pacientes adultos y adolescentes infectados por el virus de la inmunodeficiencia humana en la era del tratamiento antirretroviral de gran actividad. Recomendaciones del Grupo de Estudio del Sida (GESIDA)/Plan Nacional sobre el Sida [Treatment of opportunistic infections in adolescent and adult patients infected with the human immunodeficiency virus during the era of highly active antiretroviral therapy. AIDS Study Group (GESIDA) and National AIDS Plan Expert Committee]. Enferm Infecc Microbiol Clin 2008; 26: 356-379.

150 Department of Health and Human Services USA. Guidelines for the use of antiretroviral agents in HIV-1-infected adults and adolescents. Developed by the HHS Panel on Antiretroviral Guidelines for Adults and Adolescents. Department of Health and Human Services, 2009; 1-161. www.aidsinfo.nih.gov/ ContentFiles/AdultandAdolescentGL.pdf. Date last accessed: July 7, 2010.

151 Thompson MA, Aberg JA, Cahn P, et al. Antiretroviral treatment of adult HIV infection: 2010 recommendations of the International AIDS Society-USA panel. JAMA 2010; 304: 321-333.

152 Huang L, Quartin A, Jones D, et al. Intensive care of patients with HIV infection. N Engl J Med 2006; 355: 173-181.

153 Torres A, El-Ebiary M, Marrades R, et al. Aetiology and prognosis factors of patients with AIDS presenting life-threatening acute respiratory failure. Eur Respir J 1995; 8: 1922-1928.

154 Corona A, Raimondi F. Caring for HIV-infected patients in the ICU in the highly active antiretroviral therapy era. Curr HIV Res 2009; 7: 569-579. 
155 Powell K, Davis JL, Morris AM, et al. Survival for patients with HIV admitted to the ICU continues to improve in the current era of combination antiretroviral therapy. Chest 2009; 135: 11-17.

156 Alves C, Nicolás JM, Miró JM, et al. Reappraisal of the aetiology and prognostic factors of severe acute respiratory failure in HIV patients. Eur Respir J 2001; 17: 87-93.

157 Barbier F, Coquet I, Legriel S, et al. Etiologies and outcome of acute respiratory failure in HIV-infected patients. Intensive Care Med 2009; 35: 1678-1686.

158 Dickson SJ, Batson S, Copas AJ, et al. Survival of HIV infected patients in the intensive care unit in the era of highly active antiretroviral therapy. Thorax 2007; 62: 964-968.

159 Olaechea PM, Alvarez-Lerma F, Sánchez M, et al. Evaluation of the status of patients with severe infection, criteria for intensive care unit admittance. Spanish Society for Infectious Diseases and Clinical Microbiology. Spanish Society of Intensive and Critical Medicine and Coronary Units. Enferm Infecc Microbiol Clin 2009; 27: 342-352.

160 Masur H. Caring for AIDS patients in the ICU: expanding horizons. Chest 2009; 135: 1-2.

161 Walzer PD, Evans HE, Copas AJ. Early predictors of mortality from Pneumocystis jirovecii pneumonia in HIV-infected patients: 1985-2006. Clin Infect Dis 2008; 46: 625-633.

162 Safrin S, Finkelstein DM, Feinberg J, et al. Comparison of three regimens for treatment of mild to moderate Pneumocystis carinii pneumonia in patients with AIDS. A double-blind, randomized, trial of oral trimethoprim-sulfamethoxazole, dapsone-trimethoprim, and clindamycin-primaquine. ACTG 108 Study Group. Ann Intern Med 1996; 124: 792-802.

163 Gagnon S, Boota AM, Fischl MA, et al. Corticosteroids as adjunctive therapy for severe Pneumocystis carinii pneumonia in the acquired immunodeficiency syndrome. A doubleblind, placebo-controlled trial. $N$ Engl J Med 1990; 323: 1444-1450.

164 Fei MW, Kim EJ, Sant CA, et al. Predicting mortality from HIVassociated Pneumocystis pneumonia at illness presentation: an observational cohort study. Thorax 2009; 64: 1070-1076.

165 Tumbarello M, Tacconelli E, de Gaetano K, et al. Bacterial pneumonia in HIV-infected patients. Analysis of risk factors and prognosis indicators. J Acquir Immune Defic Syndr 1998; 16 39-45.

166 Cordero E, Pachon J, Rivero A, et al. Community-acquired bacterial pneumonia in human immunodeficiency virus-infected patients: validation of severity criteria. Am J Respir Crit Care Med 2000; 162: 2063-2068.

167 Christensen D, Feldman C, Rossi P, et al. HIV infection does not influence clinical outcomes in hospitalized patients with bacterial community-acquired pneumonia: results from the CAPO international cohort study. Clin Infect Dis 2005; 4: 554-556.

168 Feldman C, Klugman KP, Yu VL, et al. Bacteraemic pneumococcal pneumonia: impact of HIV on clinical presentation and outcome. J Infect 2007; 55: 125-135. 